\title{
Is activated factor VII associated with retinal vein occlusion?
}

\author{
Sibel Kadayifçilar, Düzgün Özatli, Osman İ Özcebe, E Cumhur Şener
}

\begin{abstract}
Aim-To determine whether a newly identified thrombophilia factor, activated factor VII (FVIIa), is associated with retinal vein occlusion (RVO).

Methods-54 consecutive cases with RVO seen between March and September 1999 were included in the study. 22 cases had central retinal vein occlusion (CRVO) and 32 had branch retinal vein occlusion (BRVO). Ophthalmoscopic examination with detailed medical history was followed by blood analyses for liver and renal functions, cholesterol, triglycerides, complete blood count, and coagulation factors including protein $\mathbf{C}$ activity, free protein $\mathbf{S}$, antithrombin III, fibrinogen, and factor VIIa (FVIIa). Data were compared with those of the control group, composed of 19 cases under ophthalmological follow up for refractive errors, presbyopia, or senile cataract.

Results-Hypertension was highly prevalent in cases with BRVO. Complete blood count, and liver and kidney function tests were within normal limits in the study group. Two cases had low protein $\mathrm{C}$ activity, and one had low free protein S. FVIIa levels were significantly higher in the RVO group than in the control group $(p=0.0004)$. There was no significant difference in FVIIa levels between the CRVO and BRVO groups $(\mathrm{p}=0.51)$.

Conclusion-No haematological parameter except FVIIa differed significantly from that of the control group. Elevation of FVIIa level may play a part in the pathophysiology of both CRVO and BRVO.

(Br F Ophthalmol 2001;85:1174-1178)
\end{abstract}

Correspondence to: Dr Sibel Kadayifçilar, Hacettepe Üniversitesi, Göz Hastaliklari Anabilim Dali, 06100 Sihhiye, Ankara, Turkey

sibelkd@mailcity.com

Accepted for publication 20 April 2001

Retinal vein occlusion (RVO) is a common cause of visual loss. Systemic disorders such as hypertension, diabetes mellitus, arteriosclerosis, and cardiovascular diseases have been implicated in the pathogenesis. ${ }^{1}$ Although a common underlying mechanism is not clear,

Table 1 Demographical characteristics of the patients

\begin{tabular}{llll}
\hline & $\begin{array}{l}C R V O+H R V O \\
\text { No }(\%)\end{array}$ & $\begin{array}{l}\text { BRVO } \\
\text { No (\%) }\end{array}$ & $\begin{array}{l}\text { Control } \\
\text { No (\%) }\end{array}$ \\
\hline Hypertension & $8(36.3)$ & $25(78.1)^{\star}$ & $6(31.6)$ \\
CAD & $2(9)$ & $2(6.2)$ & $2(10.5)$ \\
DM & $1(4.5)$ & $5(15.6)$ & $2(10.5)$ \\
Smoking & $3(13.5)$ & $5(15.6)$ & $3(15.9)$ \\
Oral contraceptive use & 0 & $1(3.1)$ & 0 \\
DVT/pulmonary embolism & 0 & 0 & 0 \\
\hline
\end{tabular}

$\mathrm{CRVO}=$ central retinal vein occlusion; $\mathrm{BRVO}=$ branch retinal vein occlusion; $\mathrm{HRVO}=$ hemiretinal vein occlusion; $\mathrm{CAD}=$ coronary artery disease $; \mathrm{DM}=$ diabetes mellitus; $\mathrm{DVT}=$ deep venous thrombosis.

${ }^{\star}$ Statistically significant difference from controls. the precise pathological event in all is the development of intraluminal thrombus. ${ }^{1}$ In many cases with RVO various factors leading to a hypercoagulable state and thus predisposing to thromboembolism can be found. ${ }^{2}$ Hereditary deficiencies of the anticoagulant proteins antithrombin, protein $\mathrm{C}$, and protein $S$ have been reported in patients with $\mathrm{RVO}^{3}{ }^{4}$ Resistance to activated protein $\mathrm{C}$, which inhibits activated coagulation factor $\mathrm{V}$ due to factor $\mathrm{V}$ Leiden mutation, was recently shown to be increased fourfold in a group of patients below 50 years of age with central retinal vein occlusion (CRVO). ${ }^{5}$ However, in older cases with CRVO activated protein $\mathrm{C}$ resistance was not found to be significant. ${ }^{6}$

The basal functional state of the coagulation system was recently found to be determined by the extent of factor VII activation. ${ }^{7}$ Elevated levels of activated factor VII (FVIIa) have been found in diseases associated with thrombotic vascular complications such as atherosclerosis or associated with cardiovascular risk factors. ${ }^{7-9}$

There is only one study disclosing higher FVII:C (coagulation activity) levels in CRVO. ${ }^{10}$ To the best of our knowledge the present study is the first to assess the role of FVIIa as a key enzyme of the coagulation cascade in RVO.

\section{Patients and methods}

Between March and September 1999, 22 cases with central and 32 cases with branch retinal vein occlusion were enrolled in this observational study. The cases comprised acute onset or follow up cases previously diagnosed with RVO. The diagnosis of RVO was made clinically with subsequent fundus fluorescein angiography to document retinal ischaemia.

The details of medical history were carefully documented including hypertension, cardiovascular disease, known or suspected diabetes mellitus, oral contraceptive or oestrogen use, smoking, previous thromboembolic events including deep venous thrombosis and pulmonary embolism, family history of thromboembolic events, previous operations, and current medication (Table 1). The precise time of occlusion could not be ascertained in many cases with BRVO. According to the interval between the probable time of occlusion and the examination the cases were analysed in three groups as follows: group 1 less than 1 month (nine cases with CRVO, seven with BRVO); group 2, 1-3 months (six cases with CRVO, seven with BRVO); group 3 more than 3 months (seven cases with CRVO, 21 with BRVO).

At the time of enrolment the laterality of involvement, intraocular pressures, presence of retinal ischaemia, rubeosis iridis, angle or 
posterior segment neovascularisation were recorded.

After complete physical examination including blood pressure measurement, blood samples were obtained for analysis of fasting blood sugar, liver and renal function tests, serum triglycerides, and cholesterol. Haematological tests included complete blood count, erythrocyte sedimentation rate (ESR), prothrombin time, international normalised ratio (INR), thrombin time, activated partial thromboplastin time (aPTT), fibrinogen (measured by the clotting method of Clauss; STA-Fibrinogen Diagnostica Stago Asnieres, France), antithrombin III activity (determined by a chromogenic assay; STA-Stachrom AT III Diagnostica Stago Asnieres, France), protein C activity (measured by synthetic chromogenic substrate method; STA-Stachrom Protein C Diagnostica Stago Asnieres, France), free protein $\mathrm{S}$ (measured with a specific enzyme linked immunosorbent assay, Asserachromfree protein-S assay; Diagnostica Stago Asnieres, France), anticardiolipin antibodies (determined with an enzyme linked immunosorbent assay; OR-GenTeec, Mainz, Germany), and FVIIa (measured by clotting assay with Staclot VIIa-rTF kit Diagnostica Stago Asnieres, France) assays. Functional activated protein $\mathrm{C}$ (APC) resistance is expressed as the ratio of aPTT in the presence of APC to aPTT in its absence.

Blood pressures and blood test results were compared with those of an age and sex matched contemporaneous control group consisting of 19 cases of the same referral area who applied for refractive errors, presbyopia, or cataract and volunteered for the study. Volunteers with history of hypertension, diabetes mellitus, or coronary artery disease were not excluded. Blood samples were obtained from one control patient concurrently with one patient with CRVO and two or three patients with BRVO.

Informed consent was obtained from the cases and the controls; no institutional review board approval was required for this study.

Statistical analyses were carried out using the Statistical Package for Social Sciences software. The $\chi^{2}$ test, Fisher's exact test, $\chi^{2} t$ test, Mann-Whitney U test, and Spearman correlation coefficient were used and a $p$ value less than 0.05 was considered statistically significant.

\section{Results}

Thirty men and 24 women aged $31-87$ years (mean 59.7 (SD 12)) were included in the study. Nineteen subjects (12 men, seven women) aged 33-81 years (mean 62.4 (10)) comprised the control group. There was no statistically significant difference between the study group and the control group with regard to age $(t=0.96, \mathrm{p}=0.63)$ and sex distribution $\left(\chi^{2}=0.332, p=0.564\right)$. Eighteen cases $(33.3 \%$; 11 men, seven women) had CRVO, four cases (7.4\%; two men, two women) had hemiretinal vein occlusion, and 32 cases $(59.3 \% ; 17$ men, 15 women) had BRVO. The cases with hemiretinal vein occlusion were added to the group of cases with CRVO as these two conditions are considered to be pathophysiologically similar. ${ }^{11}$

None of the cases or controls had been smoking for the past 3 months. The history was positive for smoking in three cases with CRVO, five cases with BRVO, and in three controls. None of the cases or controls had experienced deep venous thrombosis or pulmonary embolism. One woman with BRVO had used oral contraceptives for 3 months 5 years previously (Table 1).

Thirty three cases $(61 \%)$ had a history of hypertension. However, blood pressures were controlled medically in 18 of them (54.5\%). In the controls, six had hypertension $(31.6 \%)$, three of which were under medical control (Table 1). Two cases in each group had coronary artery disease (Table 1). Statistical analyses did not reveal significant difference between RVO group and the control group with regard to presence of coronary artery disease $(p=0.49)$ or diabetes mellitus $(p=0.65)$. However, a significant difference between the groups was observed in the parameter of systemic hypertension $\left(\chi^{2}=4.92, \mathrm{p}=0.026\right)$. When the RVO group was subdivided into CRVO and BRVO, the control group differed significantly from the BRVO group but not from the CRVO group with regard to presence of hypertension (BRVO $v$ control: $\chi^{2}=10.831$, $\mathrm{p}=0.001 ;$ CRVO $v$ control: $\chi^{2}=0.104$, $\mathrm{p}=0.747)$ and hypercholesterolaemia (BRVO $v$ control: $\chi^{2}=12.611, \mathrm{p}=0.000$; CRVO $v$ control: $\chi^{2}=0.248, p=0.618$ ) (Tables 1 and 2). The prevalence of coronary artery disease, diabetes mellitus, or hypertriglyceridaemia in CRVO and BRVO did not differ significantly from controls. None of the patients was taking

Table 2 Clinical and haematological characteristics of the patients

\begin{tabular}{llll}
\hline & $\begin{array}{l}\text { CRVO + HRVO } \\
\text { No (\%) }\end{array}$ & $\begin{array}{l}\text { BRVO } \\
\text { No (\%) }\end{array}$ & $\begin{array}{l}\text { Control } \\
\text { No (\%) }\end{array}$ \\
\hline$\uparrow$ triglycerides & $2(9)$ & $6(18.8)^{\star}$ & $4(21)$ \\
$\uparrow$ cholesterol & $8(36.3)$ & $22(68.8)^{\star}$ & $5(26.3)$ \\
$\downarrow$ protein C activity & $1(4.5)$ & $1(3.1)$ & 0 \\
APCR & 0 & $1(3.1)$ & 0 \\
$\downarrow$ free protein S & 0 & $1(3.1)$ & 0 \\
$\downarrow$ atIII activity & $1(4.5)$ & 0 & $1(5.3)$ \\
WBC $\left(\times 10^{6} / \mathrm{l}\right)(\mathrm{mean})$ & $3800-10600(6970)$ & $4500-14100(6800)$ & $4700-10680(7150)$ \\
Haemoglobin (g/dl) (mean) & $12.5-16.6(14.47)$ & $12.1-15.5(13.87)$ & $10.8-17.5(14.48)$ \\
Thrombocytes ( $\left.\times 10^{9} / 1\right)(\mathrm{mean})$ & $156-317(205)$ & $189-499(222)$ & $200-329(207)$ \\
Factor VIIa (mU/ml) (median) & $16.1-1434^{\star}(74)$ & $28-1309^{\star}(89.8)$ & $9.9-99.6(41.6)$ \\
Fibrinogen (mg/dl) (mean) & $253-493(363.5)$ & $234-530(349.3)$ & $270-700(358.2)$ \\
\hline
\end{tabular}

$\mathrm{CRVO}=$ central retinal vein occlusion; $\mathrm{BRVO}=$ branch retinal vein occlusion; $\mathrm{HRVO}=$ hemiretinal vein occlusion; $\mathrm{APCR}=$ activated protein $\mathrm{C}$ resistance; atIII = antithrombin III; $\mathrm{WBC}=$ white blood cell.

* Statistically significant difference from controls. 


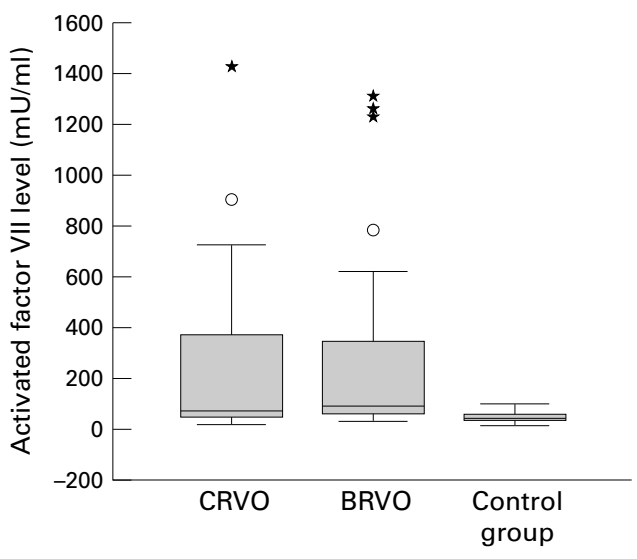

Figure 1 Activated factor VII levels in central retinal vein occlusion (CRVO), branch retinal vein occlusion (BRVO), and control group. The black lines in the box plot diagram show the median values of the groups $(\mathrm{O}=$ outlier cases,

any medication affecting the coagulation system. Two cases with CRVO had a history of open angle glaucoma $(3.7 \%)$ and were receiving antiglaucoma medications.

The complete blood counts including thrombocytes were within normal limits in all RVO cases. In the control group, one had iron deficiency anaemia (Table 2). None of the cases either in the study group or in the control group had elevated prothrombin levels, activated partial thromboplastin time, or thrombin time. Two cases with CRVO, three cases with BRVO, and two of the controls had elevated fibrinogen (normal 144-430 mg/dl, for our laboratory). One case with CRVO and one case with BRVO had low protein C activity $(65 \%$ and $44 \%$ respectively; normal $70 \%-130 \%$ for our laboratory) and the one with BRVO had APCR. One case with BRVO had low free protein $S(43 \%$, normal $60 \%-130 \%$ for our laboratory). One CRVO case $(1.8 \%)$ had low antithrombin III activity $(60 \%$, normal $80 \%$ $120 \%$ ) (Table 2). None of the cases or the controls had elevated levels of anticardiolipin antibodies.

Factor VIIa levels were significantly elevated in cases with RVO compared with the controls (normal 27.1-103.2 mU/ml) ( $\mathrm{p}=0.0004$ ) (Fig 1). There was no significant difference between CRVO and BRVO groups with regard to FVIIa levels $(p=0.51)$ (Fig 1). Factor VIIa levels higher than $120 \mathrm{mU} / \mathrm{ml}$ were found in nine cases with CRVO (40.9\%) and in 14 cases with BRVO $(43.75 \%)$, but in none of the controls. This difference in prevalence was statistically significant $(p=0.003)$. Factor VIIa level was not correlated with either systolic or diastolic pressures $\left(r_{\mathrm{s}}=0.15, \mathrm{p}=0.19 ; r_{\mathrm{s}}=0.13, \mathrm{p}=\right.$ 0.30 , respectively). There was no significant difference between FVIIa levels of hypertensive versus normotensive cases in the CRVO group $(\mathrm{u}=41, \mathrm{p}=0.585), \mathrm{BRVO}$ group $(\mathrm{u}=0.67, \mathrm{p}$ $=0.715)$ or in controls $(\mathrm{u}=31, \mathrm{p}=0.924)$.

FVIIa levels in the cases with coronary artery disease in CRVO and control groups were within normal limits (CRVO: 26.7 $\mathrm{mU} / \mathrm{ml}$, $55.5 \mathrm{mU} / \mathrm{ml}$; controls: $44.7 \mathrm{mU} / \mathrm{ml}$, $99.6 \mathrm{mU} / \mathrm{ml}$ ) but elevated in BRVO group (111 $\mathrm{mU} / \mathrm{ml}$ and $180 \mathrm{mU} / \mathrm{ml}$ ).
There was low correlation between FVIIa levels and total cholesterol levels $\left(r_{\mathrm{s}}=0.23, \mathrm{p}=\right.$ $0.074)$. However no significant correlation with triglyceride levels was observed $\left(r_{\mathrm{s}}=\right.$ $-0.89, \mathrm{p}=0.498)$. A significant association of FVIIa with HDL $\left(r_{\mathrm{s}}=0.28, \mathrm{p}=0.035\right)$, but not with LDL $\left(r_{\mathrm{s}}=0.117, \mathrm{p}=0.4\right)$ or VLDL $\left(r_{\mathrm{s}}=\right.$ $0.026, \mathrm{p}=-0.414)$ was determined. No correlation was found between fibrinogen and FVIIa levels $\left(r_{\mathrm{s}}=0.16, \mathrm{p}=0.21\right)$.

There was no statistically significant difference in FVIIa levels between patients younger than 50 years of age $(n=13)$, and those 50 and over $(\mathrm{u}=181.5, \mathrm{p}=0.13)$. When comparing patients who were diagnosed with BRVO in less than or more than 1 month, there was no statistically significant difference in the FVIIa levels ( $p=0.73)$; however, a trend towards elevated FVIIa levels was noted in patients with CRVO who were diagnosed in less than 1 month $(\mathrm{p}=0.07)$.

\section{Discussion}

Retinal vein occlusion is a condition of multifactorial pathogenesis. There are four basic pathological processes in RVO that can occur via multiple mechanisms: abnormalities of the vessel wall (endothelial dysfunction or damage), abnormal haematological factors, abnormal blood flow (abnormal rheology), and abnormal perivascular status. ${ }^{1}$ Abnormal haematological factors associated with RVO include primary hypercoagulable states because of a defect in the physiological anticoagulation mechanism such as protein C deficiency, protein $\mathrm{S}$ deficiency, activated protein $\mathrm{C}$ resistance, antithrombin III deficiency, hyperlipoproteinaemia a, abnormal platelet function, and secondary hypercoagulable states, including hyperviscosity syndromes, such as polycythaemia, leukaemia, multiple myeloma, malignancy, the presence of lupus anticoagulant, and the use of oral contraceptives. ${ }^{4}$ Secondary hypercoagulable states were not identified in any of our RVO cases, though lupus anticoagulant was not fully ruled out for which a clotting assay, like the dilute Russell viper venom assay, is required. ${ }^{12}$

Recent studies have revealed the role of the extrinsic or tissue factor dependent coagulation pathway in thromboembolic events. ${ }^{78}$ It is known that the extrinsic coagulation pathway is initiated by FVIIa, together with its cofactor, protein tissue factor, by activating factor IX and X. Factor VIIa is a glycoprotein consisting of two polypeptide chains. It is derived from an intrachain cleavage of the single chain factor VII, when factor VII is activated by the factors XIIa, IXa, Xa, IIa, and also VIIa (feedback autoactivation). Factor VII exists in plasma both as the inactive form and the enzymatically active form. ${ }^{13}{ }^{14}$ The concentration of FVIIa in plasma is approximately $1 \%$ of that of factor VII.

FVIIa deficiency causes bleeding. However, elevated plasma levels of FVIIa have been shown to be correlated with ischaemic cardiac events including acute myocardial infarction and cerebrovascular events in several large prospective epidemiological studies. ${ }^{715}$ In this 
study a total of six cases from CRVO, BRVO, and control groups were found to have coronary artery disease, with higher FVIIa levels in the two cases with BRVO.

Elevated activated factor VII levels associated with RVO have been reported only in one study. Bandello et al have disclosed higher factor VII:C (coagulation activity) levels associated with high lipoprotein a levels in 12 of 40 CRVO cases (30\%) and four of 40 controls $(10 \%) .{ }^{10}$ To the best of our knowledge, elevated FVIIa levels have not been previously reported in association with CRVO and BRVO. Previously employed FVII:C assays which were not free of interference from zymogen FVII, measured both FVII and FVIIa levels in plasma, which led to controversy over whether elevated levels of FVIIa per se, or of total FVII + FVIIa, are more closely associated with increased risk of thrombosis. ${ }^{14}$ Recently, a new assay that enables direct measurement of FVIIa in plasma has been developed. This assay is specific for FVIIa and is free of interference by zymogen factor VII. ${ }^{14}$ With this specific assay, FVIIa levels were found to be elevated in $40.9 \%$ of cases with CRVO and $43.75 \%$ of cases with BRVO in our study.

One other previous study disclosed lower FVIIa levels in cases that developed iris neovascularisation. ${ }^{17}$ In our study only one case with CRVO developed iris neovascularisation and the FVIIa level in that case (FVIIa $=131$ $\mathrm{mU} / \mathrm{ml}$ ) was neither significantly lower nor higher than that of the other RVO cases.

Hypertension was found to be a significant systemic association with cases with BRVO but not with CRVO. Increasing laboratory and clinical evidence suggests that hypertension itself may confer a prothrombotic or hypercoagulable state. ${ }^{18}$ One previous study revealed a statistically significant decrease in activated protein $\mathrm{C}$ levels in hypertensive RVO patients when compared with RVO patients without hypertension. ${ }^{3}$ In this study, both cases with low activated protein $\mathrm{C}$ levels had a history of hypertension, but the case with low protein $S$ did not. Levels of activated factor VII did not statistically differ in cases with or without hypertension. Again, no correlation was found between FVIIa and blood pressure levels.

In this study plasma FVIIa levels did not exhibit any significant correlation with plasma fibrinogen. Previous studies are controversial; one documented no significant correlation ${ }^{14}$ but another did show a positive correlation. ${ }^{19}$

One previous study reporting increased procoagulant activity of factor VII in a patient with congenital protein $\mathrm{C}$ deficiency who developed acute myocardial infarction suggested that concomitant factor VII hyperactivity might cause arterial thrombosis in patients with protein $\mathrm{C}$ deficiency. ${ }^{20}$ However, in our two cases with low protein $\mathrm{C}$ activity FVIIa levels were within normal limits.

Hypercholesterolaemia was found to be significantly associated with BRVO, as in one previous study, ${ }^{21}$ in which it was concluded that the increase in serum lipids may contribute to the aetiology of RVO by altering plasma viscosity or affecting platelet function. Previous reports disclosed a correlation of FVII:C with serum levels of total cholesterol, triglycerides, and HDL-C, but no statistically significant correlation of FVIIa with total cholesterol and triglyceride levels. ${ }^{19}$ Our study confirmed most of these findings, as no significant correlation between FVIIa and total cholesterol or triglyceride levels was observed. However, significant correlation between FVIIa and HDL levels was found, which should be further investigated with larger scale studies.

In conclusion, the results of our study demonstrated elevated FVIIa levels in a series of patients with RVO. None of the other haematological parameters tested was found to be significantly different from those of the control group. Thus, our study points to an association between elevated plasma levels of FVIIa and RVO, as in other thromboembolic events. In both CRVO and BRVO, two conditions with different aetiological factors, ${ }^{17}$ FVIIa has been shown to be related to increased thrombosis, but the mechanism of this increase remains to be elucidated. Elevated FVIIa levels may be a consequence of the actual thrombotic event and not a direct cause of RVO. This issue can be clarified with further longitudinal studies with follow up FVIIa levels.

Based only on the results of this study, without other concomitant risk factors or thromboembolism history, no systemic therapeutic intervention, such as anticoagulation, can be recommended for patients with RVO and elevated FVIIa levels at this time. Results of further clinical studies are indispensable for the optimal therapeutic approach. Association of elevated FVIIa levels with cardiac and cerebral ischaemic events necessitates the avoidance of other risk factors, like smoking or oral contraceptive use. Closer follow up for thromboembolic events is advisable. If surgery or immobilisation is required later in life, prophylaxis against thrombosis may be considered.

The authors thank Professor Bora Eldem for referral of patients, $\mathrm{Mr}$ Serafettin Kirazli for technical assistance, and Professor Ergun Karadgaoglu for statistical assistance.

1 Bhagat N, Goldberg MF, Gascon P, et al. Central retinal vein occlusion: review of management. Eur $\mathcal{F}$ Ophthalmol 1999;9:165-80.

2 Lip PL, Blann AD, Jones AF, et al. Abnormalities in haemorheological factors and lipoprotein (a) in retinal vascular occlusion: implications for increased vascular risk. Eye 1998;12:245-51.

3 Sener EC, Özdemir O, Oruç S, et al. Retina ven tikaniklidina elik eden antikoagülan ve fibrinolitik faktör eksiklikleri (Retinal vein occlusion associated with deficiency of anticoagulant and fibrinolytic factors: protein $C$ and

protein S).(English abstract) Thre Oft $\mathrm{Gaz} 1992 ; 22: 371-5$. Vine AK, Samama MM. The role of abnormalities in the anticoagulant and fibrinolytic systems in retinal vascular occlusions. Surv Ophthalmol 1993;37:283-92.

5 Larsson J, Olafsdottir E, Bauer B. Activated protein C resistance in young adults with central retinal vein occlusion. Br f Ophthalmol 1996;80:200-2.

6 Larsson J, Sellman A, Bauer B. Activated protein C resistance in patients with central retinal vein occlusion. $\mathrm{Br}$ f Ophthalmol 1997;81:832-4.

7 Miller GJ, Wilkes HC, Meade TW, et al. Haemostatic changes that constitute the hypercoagulable state. Lancet 1991;338:1079

8 Meade TW, Mellows S, Brozovic M, et al. Haemostatic function and ischaemic heart disease: principal results of the Northwick Park Heart Study. Lancet 1986;2:533-7.

9 Kapiotis S, Jilma B, Pernerstorfer T, et al. Plasma levels of activated factor VII decrease during the menstrual cycle.
Thromb Haemost 1998;80:588-91.

10 Bandello F, Vigano' D'Angelo S, Parlavecchia M, et al. Hypercoagulability and high lipoprotein (a) levels in patients with central retinal vein occlusion. Thromb Haemost 1994;72:39-43. 
11 Hayreh SS. Central retinal vein occlusion. Ophthalmol Clin North Am 1998;11:559-90.

12 Petri M Nelson $\mathrm{W}$ Weimer $\mathrm{F}$, et al. The automated modified Russell viper venom time test for the lupus anticoagulant. $\mathcal{F}$ Rheumatol 1991;18:1823-5.

13 Bauer KA. Activation of the factor VII-tissue factor pathway. Thromb Haemost 1997;78:108-1

14 Morrissey JH, Macik BG, Neuenschwander PF, et al. Quantitation of activated factor VII levels in plasma using a tissue factor mutant selectively deficient in promoting factor VII activation. Blood 1993;81:734-44

15 Kelleher CC. Plasma fibrinogen and factor VII as risk factors for cardiovascular disease. Eur 7 Epidemiol 1992;8: $79-82$

16 Heinrich J, Balleisen L, Schulte H, et al. Fibrinogen and factor VII in the prediction of coronary risk. Results from the PROCAM study in healthy men. Arterioscler Thromb 1994; 14:54-9.
17 Williamson TH, Rumley A, Lowe GDO. Blood viscosity, coagulation, and activated protein $\mathrm{C}$ resistance in central etinal vein occlusion: a population controlled study. $\mathrm{Br} f$ Ophthalmol 1996;80:203-8.

18 Lip GYH, Blann AD. Does hypertension confer a prothrombotic state? Virchow's triad revisited. Circulation 2000;101:218-20.

19 Kario K, Miyata T, Sakata T, et al. Fluorogenic assay of activated factor VII. Plasma factor VIIa levels in relation to arterial cardiovascular diseases in Japanese. Arterioscler Thromb 1994;14:265-74.

20 Kario K, Matsuo T, Tai S, et al. Congenital protein C deficiency and myocardial infarction: concomitant factor VII hyperactivity may play a role in the onset of arterial thrombosis. Thromb Res 1992;67:95-103.

21 Dodson PM, Galton DJ, Hamilton AM, et al. Retinal vein occlusion and the prevalence of lipoprotein abnormalities. Br f Ophthalmol 1982;66:161-4. 